\begin{tabular}{|c|c|c|}
\hline 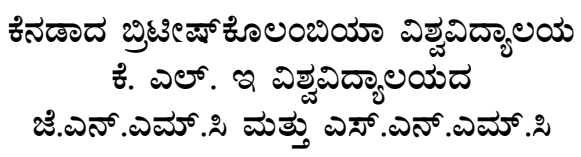 & 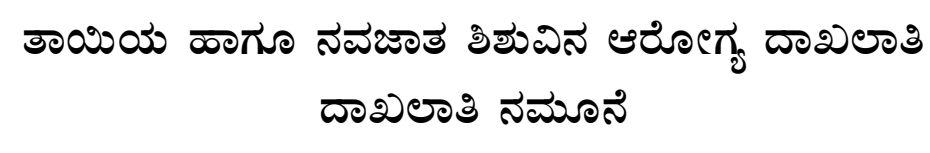 & ఎమో.ఎనా 01 \\
\hline ఝుట3 1 రల్లి 1 & 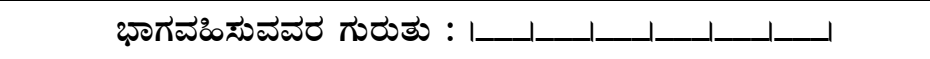 & ఆळతేరణే 2.0 జృతృ 16, 2013 \\
\hline
\end{tabular}

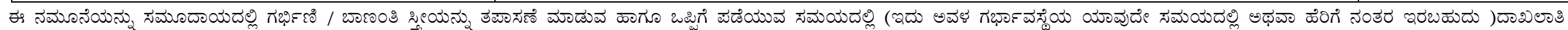

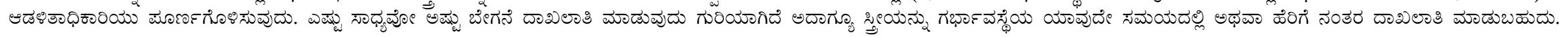

\section{అాయియ దోరింి}

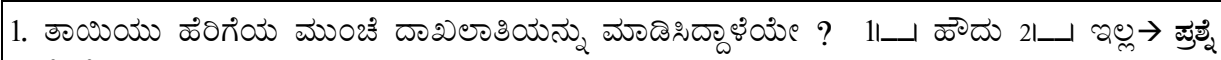
అ3혀

2. య์อcజిత ळరిగి స్థథ

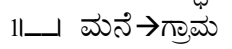

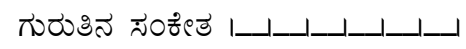

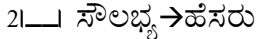

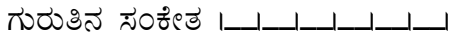

31_- ఇతరి, నఋూంది

$41 \_$గis.త్తిల

3. అందాజిసిద ळరిగియ దినాంళ

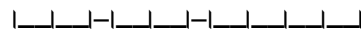

(గึ่త్తిరదిద్దరా 999 ఎండు నమాఠదిసి)

ద ద 3030 బ

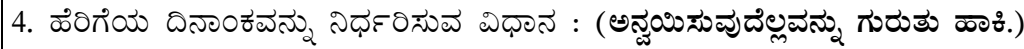
11— పోఠనియ మొట్టిన దనాంళ :
అ. | $\mid$
(గீ่త్రిరదిద్దరి 999 ఎండు నజాอదిసి)
ది ది 3030 బ

21__ వ్లై
31__ అలల్ట్రైండా

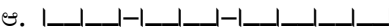

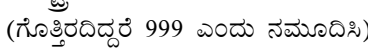
ద ద 3080 బ $\widetilde{\omega}$

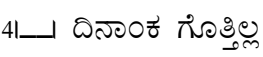

$51 \_$ఇతోరి $\rightarrow$ 凤.

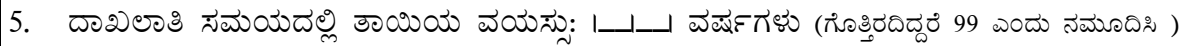

6. उాయియ లాలా డెట్టె :

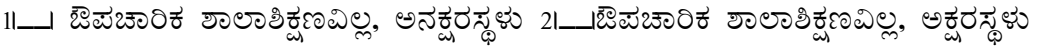

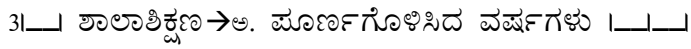

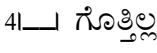

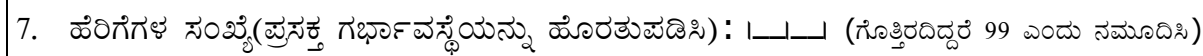

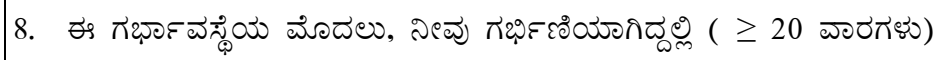

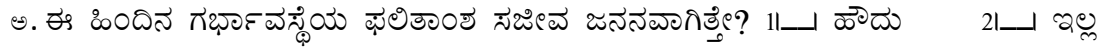

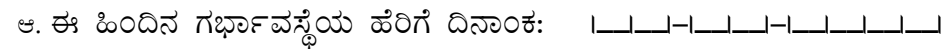

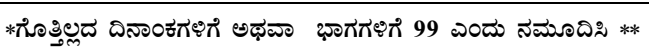

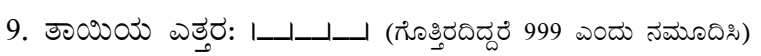

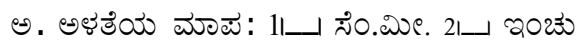

బ. బత్తర నిథణరిడ విధాన

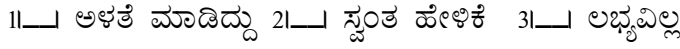

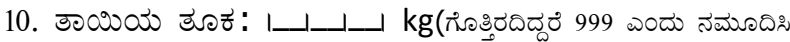

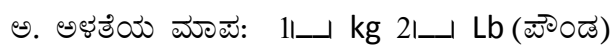

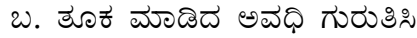

$11 \_$గభ६ ధారణయ

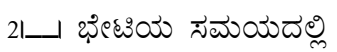

$31 \_$ఇరరర $\rightarrow$ నณூందిసి.

ซ. ฮృళ నిధణరిబ బిధాన

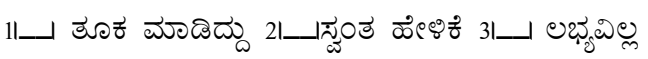

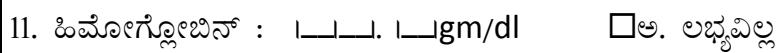

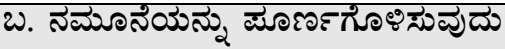

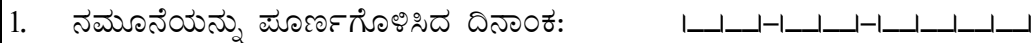

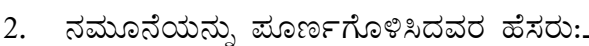

అ. กొరుతు: |-_ـ_ـ_ــ

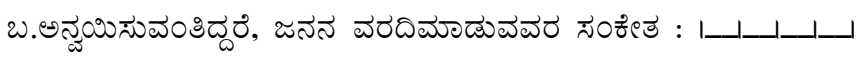

